\title{
Cost-effectiveness of endovascular therapy for acute ischemic stroke
}

Michael Chen

Correspondence \& reprint requests to Dr. Chen: Michael_Chen@rush.edu

\section{ABSTRACT}

Though rarely considered in the clinical decision algorithm, issues of cost-effectiveness assume critical importance for the sustainability of a widely used therapy that entails considerable cost and has unproven benefit. Although current data are limited, we review the studies that have demonstrated via modeling that endovascular stroke treatment may generate significant future economic benefits, even if these treatments have a high price and result in relatively small initial reductions in disability. We highlight important considerations that, on the basis of the logistics and protocols of current neuroendovascular practices, should be included in future cost-effectiveness analyses of endovascular therapy for acute ischemic stroke. Neurology ${ }^{\circledR}$ 2012;79 (Suppl 1):S16-S21

\section{GLOSSARY}

IA = intra-arterial; ICER = incremental cost effectiveness ratio; $\mathbf{L V O}=$ large vessel occlusion; $\mathbf{M E R C I}=$ Mechanical Embolus Removal in Cerebral Ischemia; $\mathbf{m R S}=$ modified Rankin Scale; NIHSS = NIH Stroke Scale; PROACT = Prolyse in Acute Cerebral Thromboembolism; QALYs = quality-adjusted life-years; SWIFT = SOLITAIRE FR With the Intention For Thrombectomy; tPA = tissue plasminogen activator; TREVO2 = Randomized Trial Evaluating Performance of the Trevo Retriever Versus the Merci Retriever in Acute Ischemic Stroke.

Of the many strategies that reduce the burden of stroke on society, including prevention measures, acute intra-arterial (IA) therapies have received a considerable amount of attention. Medicare has prioritized our health care resources toward acute endovascular stroke therapy, as demonstrated by higher diagnosis-related group reimbursements. The private sector also sees acute interventional therapies as an area of growth, as seen by the number of start-up companies designing a plethora of IA stroke devices. Many hospitals feature their stroke programs over others and invest heavily in services that can deliver on acute interventional stroke care.

At first glance, the upfront costs of delivering acute IA stroke therapy seem to be well accounted for by the long-term savings in reduced use of nursing home or rehabilitative care. However, this assumption may not be accurate in that only a minority of patients who undergo this therapy actually see a meaningful clinical benefit. ${ }^{1}$ There are also those patients who may spontaneously recanalize without the need for endovascular treatment. Furthermore, there is not currently a randomized clinical trial that demonstrates clinical efficacy of primarily mechanical devices for acute stroke therapy. Therefore, clinical effectiveness, let alone costeffectiveness, has yet to be proven or determined.

Many models have been developed that have a considerable number of assumptions built in that seem to demonstrate cost-effectiveness. Previously published studies have used models constructed to analyze the cost-effectiveness of IV thrombolytics on functional outcome. As a preliminary step, these models may be applied to study the effect of endovascular stroke therapy on reducing disability. With this information, the direct costs of providing this therapeutic option can then be compared in parallel with the cost savings of reducing disability in patients with severe strokes. These determinations may further help identify the costliest components of delivering stroke care and thereby allow effective strategies to address them. Although current

From Rush University Medical Center, Chicago, Illinois.

Go to Neurology.org for full disclosures. Disclosures deemed relevant by the authors, if any, are provided at the end of this article. 
data are limited, we will review the studies that have, via modeling, demonstrated that endovascular stroke treatment may generate significant future economic benefits, even if these treatments have a high price and result in relatively small initial reductions in disability. We also will highlight important considerations that, on the basis of the logistics and protocols of current neuroendovascular practices, should be included in future costeffectiveness analyses of endovascular therapy for acute ischemic stroke.

BACKGROUND In 1993 the Stroke Prevention Patient Outcomes Research Team estimated the total annual economic burden of stroke to be $\$ 30$ billion (US dollars). ${ }^{2}$ In an analysis of the aggregate lifetime cost of stroke, acute care costs in the first 2 years accounted for $45 \%$ of total costs, long-term ambulatory costs for $35 \%$, and nursing home costs for $17.5 \%$, suggesting a strong relationship between severity of disability and direct care costs.

Seventy-two consecutive inpatients with ischemic stroke underwent CT angiography of the brain, and it was found that intracranial large-vessel occlusion (LVO)_involving the vertebral, basilar, or middle cerebral artery or the carotid terminus-independently predicted a poor neurologic outcome at hospital discharge. More important, though, was that only $15 \%$ of patients with LVO had a favorable neurologic outcome at 30 days. $^{3}$

Although the findings may seem obvious, a prospective study in Europe of 435 consecutive patients found that modified Rankin Scale (mRS) score at hospital discharge was directly related to overall costs over the subsequent 18 months. ${ }^{4}$ The costs of caring for a patient with stroke whose mRS score is 4 or 5 (severe dependency) was 3-fold higher than for a patient with an mRS score of 2 or less, and it was $70 \%$ higher than for a patient with an mRS score of 3 .

The presence of an LVO and, therefore, handicap level, as opposed to the patient's age and stroke subtype, is potentially modifiable with IA therapies. Therefore, patients with LVO are expected to have severe disability and to need the most resources for care. Acute endovascular stroke therapy is specifically designed to recanalize LVO, restoring blood flow, with the hope of minimizing the ischemic penumbra and leading to reduced future disability and total costs.

TERMINOLOGY In order to measure the costeffectiveness of acute endovascular stroke therapy, a treatment alternative needs to be determined, which may represent either IV thrombolysis or no thrombolysis. A decision tree is then constructed to compare the 2 treatment options. At the most fundamental level, both the costs and benefits of the 2 treatment alternatives need to be compared.

Costs can be divided into those that are shared and those that are unique to IA stroke therapy. Shared costs include basic hospitalization costs, rehabilitation costs, and possible long-term care costs. Costs unique to IA stroke therapy may include rapid hospital triage and imaging, helicopter transport, and endovascular procedure costs, including the cost of catheter-based devices that are used. Obviously, though, future rehabilitation or long-term care will account for the bulk of the costs.

Indirect costs also need to be included in this analysis. One study looking at indirect stroke costs applied a human capital approach, which measures the value of foregone productivity attributable to premature morbidity and mortality. ${ }^{2}$ Using these calculations, the researchers found that indirect costs accounted for more than $82 \%$ of the lifetime cost of stroke for patients less than 45 years of age and accounted for $48 \%$ of the total for patients less than 65 years of age. Indirect costs should therefore be regarded as being nearly as much as direct medical costs, and greater costs are associated with younger patients.

Clinical effectiveness in stroke is often measured via the effect a given treatment has on the level of disability at some future date, and the mRS is a frequently used outcome measure. The difference in clinical outcome conferred by IA stroke therapy over either IV or no therapy has yet to be determined. Thus, recanalization rates, which are easier to measure, have been used as a surrogate outcome measure after thrombolysis. ${ }^{5}$ This is a fundamental limitation in any cost-effectiveness analysis, because clinical effectiveness is unknown.

Cost-effectiveness, therefore, considers both the clinical effectiveness of the health care intervention as well as the costs required to deliver the intervention. Quality-adjusted life-years (QALYs) are usually the main outcome in these types of analyses. They are calculated by multiplying the time spent in each health state by the value assigned to the particular health state. ${ }^{6}$ The values used to numerically score the desirability of various health states are termed utilities, with a range of 0 (death) to 1 (perfect health). These values are often assigned by experts or based on feedback elicited from patients. One review study proposed a QALY of 0.74 (with a range of 0.55 to 0.92 ) for an $\mathrm{mRS}$ score of 2 or less and a QALY of 0.40 (with a range of 0.30 to 0.50 ) for an mRS score of 3 to 5 . $^{7}$ 


\begin{tabular}{|c|c|c|c|c|}
\hline \multirow{2}{*}{$\begin{array}{l}\text { Table } 1 \\
\text { Cost varia }\end{array}$} & \multicolumn{4}{|c|}{$\begin{array}{l}\text { The effect of IV tPA on acute and } \\
\text { long-term care, in comparison } \\
\text { with placebo }{ }^{12}\end{array}$} \\
\hline & & IV tPA & Placebo & $p$ Value \\
\hline \multicolumn{2}{|c|}{ Mean length of stay, $d$} & 10.88 & 12.41 & 0.02 \\
\hline \multicolumn{2}{|c|}{ Disposition, \% } & & & 0.002 \\
\hline \multicolumn{2}{|c|}{ Discharged to home } & 48 & 36 & \\
\hline \multicolumn{2}{|c|}{ Discharged to rehabilitation } & 29 & 37 & \\
\hline \multicolumn{2}{|c|}{ Discharged to nursing home } & 7 & 13 & \\
\hline
\end{tabular}

Abbreviation: tPA = tissue plasminogen activator.

Finally, the incremental cost-effectiveness ratio (ICER) is the ratio that combines cost and QALY, which is calculated by dividing the difference in costs by the difference in QALYs. In general, interventions are considered cost-effective if the ICER is less than $\$ 50,000$ per QALY gained and borderline costeffective if the ratio is between $\$ 50,000$ and $\$ 100,000$ per QALY gained. ${ }^{8}$ However, this value was first determined in 1982 on the basis of the costeffectiveness ratio calculated for the use of dialysis in patients with chronic renal failure. Some researchers suggest this threshold is too low and that in fact there should be a substantially higher monetary value placed on 1 year of life without morbidity. ${ }^{9}$

Another study illustrates the complexity inherent in using disability as an outcome measure. Prior surveys of patients with symptomatic stroke led to a quality-of-life factor of 0.66 , which means that these patients would trade 10 years of life with their disability for 6.6 years of life without disability. ${ }^{10}$

PRIOR COST-EFFECTIVENESS STUDIES OF IV THROMBOLYTICS The proven clinical effectiveness of IV tissue plasminogen activator (tPA) for acute ischemic stroke led to US Food and Drug Administration approval in 1996. ${ }^{11}$ IV tPA has also been shown to be cost-effective for patients with stroke in both the United States and Canada. It was reported that in the United States, ${ }^{12}$ the average cost of tPA was $\$ 2,230$; of inpatient rehabilitation, $\$ 21,233$; and of nursing home care, $\$ 39,996$ yearly. Using a Markov model, the researchers found that in the treatment group, for every 1,000 eligible patients treated, hospitalization costs increased by $\$ 1.7$ million, rehabilitation costs decreased by $\$ 1.4$ million, and most significantly, nursing home costs decreased by $\$ 4.8$ million. Multi-way sensitivity analyses showed a $90 \%$ probability of cost savings and 564 QALYs saved over 30 years per 1,000 patients (table 1 ). ${ }^{12}$

The Canadian Institute of Health Information database ${ }^{13}$ was used to evaluate 55,841 stroke cases occurring in 1999. The researchers reported a cost-savings estimate for 2005 of $\$ 678$ (Canadian) per tPA-treated patient with acute ischemic stroke during the first posttreatment year. Based on their rate of tPA use (1.4\%), the estimated national cost savings for Canada for tPA-treated acute strokes after the first year was greater than $\$ 500,000$ (Canadian). Adjusting for a biannual $2 \%$ point inflation shows that greater than $\$ 750,000$ (Canadian) could be saved during just the first year after stroke. Optimistically, if $20 \%$ of patients with ischemic stroke received tPA, then greater than $\$ 7.5$ million (Canadian) could be saved nationwide in the first years, without even including potential reduced indirect costs, which were not included in this analysis. ${ }^{13}$

IA THROMBOLYTIC COST-EFFECTIVENESS MODELS A true cost-effectiveness analysis can be performed only when a given treatment has been proven to be clinically effective. The Prolyse in Acute Cerebral Thromboembolism (PROACT) II trial ${ }^{14}$ did demonstrate clinical effectiveness, but it used intra-arterially administered urokinase exclusively. Current neuroendovascular stroke practices, particularly with the use of mechanical devices and treatment of lesions other than M1 occlusions, are quite different. Because endovascular mechanical stroke therapy, as it is largely practiced today, has not yet been proven in a randomized trial to yield a clinical benefit, true cost-effectiveness analyses are not yet available.

Costs. Despite limitations on accurately determining clinical benefit, costs have been more accurately determined in recently published literature. Most dollar figures are actual charges to the hospital, which we will take as an approximation of the cost. It should be obvious that individual and institutional costs of delivering endovascular acute stroke therapy are substantial, requiring significant upfront investment by hospitals for staffing at all hours and device inventory. The charges for helicopter transport, a service commonly used at most busy stroke centers for thrombolysis candidates, have been estimated at $\$ 3,749 .{ }^{15}$ The professional and technical charges associated with diagnostic cerebral angiography total about \$1,500. . A 50-mg vial of tPA, for potential IA administration, is nearly $\$ 1,400 .{ }^{12}$ Hospital charges for the Merci retriever device are $\$ 2,950$; for a compatible microcatheter, $\$ 475$; for a distal access catheter, $\$ 800$; and for a balloon-guided catheter, $\$ 675$. On average, 2 retrievers are used per case (personal correspondence). The charges for each Penumbra reperfusion catheter and separator are approximately $\$ 1,050$ and $\$ 2,200$, respectively, and again, 2 full systems generally are used per stroke intervention (personal correspondence). The Penumbra Neuron 


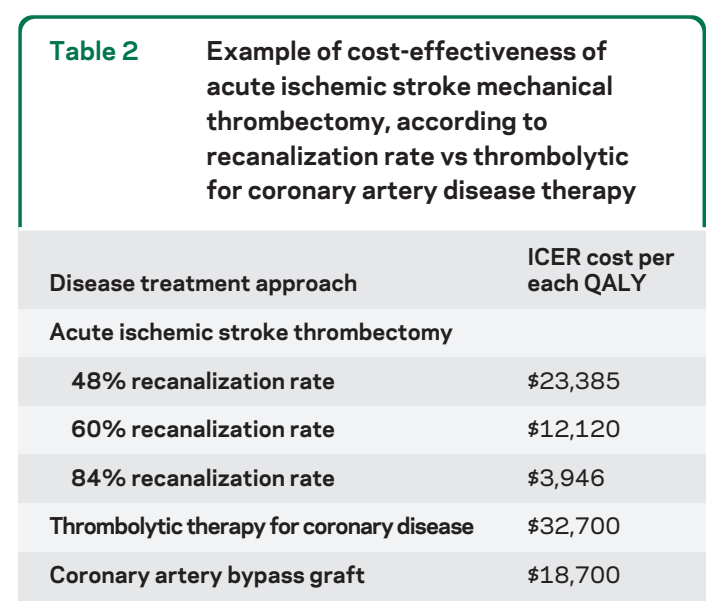

Abbreviations: ICER $=$ incremental cost-effectiveness ratio; $Q A L Y=$ quality-adjusted life-year. ${ }^{7}$

guide catheter is about $\$ 800$ (personal correspondence). Therefore, as a rough estimate, an endovascular acute stroke procedure adds on at least $\$ 10,000$ to the cost of caring for that patient.

A true cost calculation must include the resources needed to maintain the constant availability, at all hours, of the physician, nurse, technician, and anesthesiologist. Furthermore, often patients are transported by helicopter and undergo specific imaging studies (particularly perfusion imaging) because of this acute triage. Furthermore, sometimes the on-call team is activated, only to find that because of physiologic imaging, time constraints, or other access issues during angiography, the patient does not end up undergoing endovascular thrombolysis. These cases nevertheless incur the significant acute triage costs, as a part of the intention to treat.

Benefit. The next logical variable that needs to be quantified in this analysis is the clinical benefit of IA, particularly mechanical, acute stroke therapy. Currently published prospective studies of singlearm mechanical devices lack a control group and a primary outcome that directly measures clinical effectiveness.

The Multi-MERCI (Mechanical Embolus Removal in Cerebral Ischemia) ${ }^{16}$ and Penumbra ${ }^{17}$ trial results provide the largest and best representation of current IA stroke therapy practice in that, when possible, IV thrombolytics are given prior to attempting IA thrombolysis. As demonstrated in table 2, in the Multi-MERCI trial, 36\% of treated patients had a 30 -day mRS score less than or equal to 2. Although this seems less robust when compared to similar outcomes of the IV tPA ${ }^{11}$ and PROACT $\mathrm{II}^{14}$ treatment groups, the median NIH Stroke Scale (NIHSS) scores in the Multi-MERCI group and the Penumbra group were considerably higher, and both trials also included patients with basilar and carotid terminus occlusions.

The best information we have regarding the natural history of patients with an LVO would be from the PROACT II control group, where $25 \%$ had an mRS score less than or equal to $2 .{ }^{14} \mathrm{~A}$ more representative control group, one that included not only proximal middle cerebral artery occlusions but also carotid terminus and basilar occlusions, would likely have even fewer patients with a favorable clinical outcome. In the previously cited study of 72 consecutive patients with ischemic stroke, only $15 \%$ of those with LVO not treated with thrombolysis ultimately had a favorable neurologic outcome. ${ }^{3}$ This may be another piece of information that suggests what one might expect for a patient who is a candidate for IA stroke therapy but does not receive treatment. On the basis of the National Institute of Neurological Disorders and Stroke placebo group, which included many patients without LVO (as represented by the relatively lower average NIHSS scores on admission), ${ }^{12}$ the percentage of cases having a favorable outcome without treatment could be as high as $20 \% .{ }^{11}$

Therefore, the best approximation of the degree of clinical benefit would be modest at best, and it may be very much dependent on patient selection. The current data, which inherently measure the initial clinical outcomes, suggest the clinical benefit to be modest at best.

Modeling cost-effectiveness analysis. There have been published models designed to determine the costeffectiveness of acute endovascular stroke therapy but that are based on key assumptions. A study modeling a theoretical cost-effectiveness analysis of mechanical thrombectomy used a hypothetical 67-year-old, IVineligible patient treated with a Merci retriever system (Concentric Medical, CA) and compared this with the same patient treated with standard medical therapy according to American Stroke Association guidelines. ${ }^{7}$ It is unclear from their methods whether the researchers in fact chose a control case that had a large artery occlusion rather than an "average" ischemic stroke. The nature of the vascular occlusion would clearly play an important role in determining future costs. A Markov cost-effectiveness model was built to compare the 2 treatment approaches. Assumption of outcome was based on prior clinical trials, for example, a recanalization rate of $60 \%$ in the mechanical group vs $18 \%$ in the medical group, and a good clinical outcome of $36 \%$ in the mechanical group with an intracranial hemorrhage rate of $7.8 \% .{ }^{16}$ Clearly, the use of recanalization as a surrogate for differences in clinical outcome may not be entirely accurate. 
Nevertheless, the mean cost for endovascular treatment was $\$ 24,154$, in comparison with $\$ 6,749$ for standard medical therapy. The annual care for dependent, independent, and recurrent strokes was the same across the 2 groups. The study showed 2.37 QALYs gained in the mechanical thrombectomy group, vs 1.83 QALYs gained with standard medical therapy. This translated to an ICER of $\$ 12,120$ for each increase by 1.0 QALY, by implementing mechanical thrombectomy, a finding that clearly suggests this is costeffective, whichever range one would decide to be accurate. In comparison, coronary artery bypass graft and thrombolytic therapy for coronary artery disease were associated with ICERs of $\$ 18,700$ and $\$ 32,700$, respectively (table 2 ). ${ }^{7}$

FUTURE DIRECTIONS The currently published models clearly make significant assumptions on clinical benefit, but they do capture accurate data on costs. The results from the SOLITAIRETM FR With the Intention For Thrombectomy (SWIFT) Study (NCT01054560) and Randomized Trial Evaluating Performance of the Trevo Retriever Versus the Merci Retriever in Acute Ischemic Stroke (TREVO2) (NCT01270867) will provide additional prospective, standardized data on patient outcomes after mechanical thrombolysis. This will also represent a more modern practice pattern whereby patient selection has improved, all LVOs are included, and the most current iterations of mechanical thrombectomy devices are used, possibly contributing to even better patient outcomes. Future models should include the costs involved with acute triage, including helicopter transport, perfusion imaging, and staffing. Indirect costs should also be included.

The NIH-funded Interventional Management of Stroke Trial III, which has enrolled nearly 600 of the planned 900 subjects, plans to prospectively determine the cost-effectiveness of the combined IV/IA approach as compared with standard IV recombinant tPA. The trial will measure the expected differences in hospital costs, cumulative health care costs over the first year, and differences in subjects' value of their quality of life over 12 months. From these measures, researchers will calculate ICERs and cost increases/cost offsets due to the differences in therapy. ${ }^{18}$

In the future, with improved patient selection, the clinical benefits should be more robust in that fewer procedures are performed in patients who have established infarcts. With improvements in device safety and efficacy along with operator experience, we should see shorter and safer procedure durations, which may mean the use of fewer devices; if com- bined with better clinical outcomes, this will further improve cost-effectiveness. A cost-effectiveness analysis appears to be most appropriate when a therapy has matured in its limits of therapeutic efficacy. Our understanding of acute stroke pathophysiology, patient selection, system organization, device functionality, and other treatments is clearly still in its infancy.

\section{AUTHOR CONTRIBUTIONS}

M.C. participated in drafting/revising the manuscript, study concept or design, analysis or interpretation of data, study supervision, acquisition of data, and statistical analysis.

\section{DISCLOSURE}

Dr. Chen serves as Associate Editor for Frontiers in Neurology. Go to Neurology.org for full disclosures.

Received June 26, 2011. Accepted in final form October 17, 2011.

\section{REFERENCES}

1. Chen M. Acute endovascular stroke therapy. Am J Ther 2011;18:57-63.

2. Taylor TN, Davis PH, Torner JC, Holmes J, Meyer JW, Jacobson MF. Lifetime cost of stroke in the United States. Stroke 1996;27:1459-1466.

3. Smith WS, Tsao JW, Billings ME, et al. Prognostic significance of angiographically confirmed large vessel intracranial occlusion in patients presenting with acute brain ischemia. Neurocrit Care 2006;4:14-17.

4. Spieler JF, Lanoe JL, Amarenco P. Costs of stroke care according to handicap levels and stroke subtypes. Cerebrovasc Dis 2004;17:134-142.

5. Kim AS, Nguyen-Huynh M, Johnston SC. A costutility analysis of mechanical thrombectomy as an adjunct to intravenous tissue-type plasminogen activator for acute large-vessel ischemic stroke. Stroke 2011;42: 2013-2018.

6. Torrance GW. Utility approach to measuring healthrelated quality of life. J Chronic Dis 1987;40:593-603.

7. Patil CG, Long EF, Lansberg MG. Cost-effectiveness analysis of mechanical thrombectomy in acute ischemic stroke. J Neurosurg 2009;110:508-513.

8. Gold MR. Standardizing cost-effectiveness analyses: the panel on cost-effectiveness in health and medicine. Acad Radiol 1998;5(suppl 2):S351-S354.

9. Ubel PA, Hirth RA, Chernew ME, Fendrick AM. What is the price of life and why doesn't it increase at the rate of inflation? Arch Intern Med 2003;163:1637-1641.

10. Derdeyn CP, Powers WJ. Cost-effectiveness of screening for asymptomatic carotid atherosclerotic disease. Stroke 1996;27:1944-1950.

11. The National Institute of Neurological Disorders and Stroke rt-PA Stroke Study Group. Tissue plasminogen activator for acute ischemic stroke. N Engl J Med 1995;14; 333:1581-1587.

12. Fagan SC, Morgenstern LB, Petitta A, et al. Costeffectiveness of tissue plasminogen activator for acute ischemic stroke: NINDS rt-PA Stroke Study Group. Neurology 1998;50:883-890.

13. Yip TR, Demaerschalk BM. Estimated cost savings of increased use of intravenous tissue plasminogen activator for 
acute ischemic stroke in Canada. Stroke 2007;38:19521955.

14. Furlan A, Higashida R, Wechsler L, et al. Intra-arterial prourokinase for acute ischemic stroke. The PROACT II study: a randomized controlled trial: Prolyse in acute cerebral thromboembolism. JAMA 1999;282:20032011.

15. Silbergleit R, Scott PA, Lowell MJ. Cost-effectiveness of helicopter transport of stroke patients for thrombolysis. Acad Emerg Med 2003;10:966-972.
16. Smith WS, Sung G, Saver J, et al. Mechanical thrombectomy for acute ischemic stroke: final results of the Multi MERCI Trial. Stroke 2008;39:1205-1212.

17. Penumbra Pivotal Stroke Trial Investigators. The Penumbra Pivotal Stroke Trial: safety and effectiveness of a new generation of mechanical devices for clot removal in intracranial large vessel occlusive disease. Stroke 2009;40:2761-2768.

18. Mauldin PD, Simpson KN, Palesch YY, et al. Design of the economic evaluation for the Interventional Management of Stroke (III) Trial. Int J Stroke 2008;3:138-144. 


\section{Neurology}

\section{Cost-effectiveness of endovascular therapy for acute ischemic stroke Michael Chen \\ Neurology 2012;79;S16-S21 \\ DOI 10.1212/WNL.0b013e31826957df}

This information is current as of September 24, 2012

\section{Updated Information \&} Services

References

Citations

Subspecialty Collections

Permissions \& Licensing

Reprints including high resolution figures, can be found at: http://n.neurology.org/content/79/13_Supplement_1/S16.full

This article cites 18 articles, 7 of which you can access for free at: http://n.neurology.org/content/79/13_Supplement_1/S16.full\#ref-list-1

This article has been cited by 2 HighWire-hosted articles: http://n.neurology.org/content/79/13_Supplement_1/S16.full\#\#otherarti cles

This article, along with others on similar topics, appears in the following collection(s):

Cost effectiveness/economic

http://n.neurology.org/cgi/collection/cost_effectiveness_economic_

Information about reproducing this article in parts (figures,tables) or in its entirety can be found online at:

http://www.neurology.org/about/about_the_journal\#permissions

Information about ordering reprints can be found online:

http://n.neurology.org/subscribers/advertise

Neurology ${ }^{\circledR}$ is the official journal of the American Academy of Neurology. Published continuously since 1951, it is now a weekly with 48 issues per year. Copyright Copyright (? 2012 by AAN Enterprises, Inc.. All rights reserved. Print ISSN: 0028-3878. Online ISSN: 1526-632X.

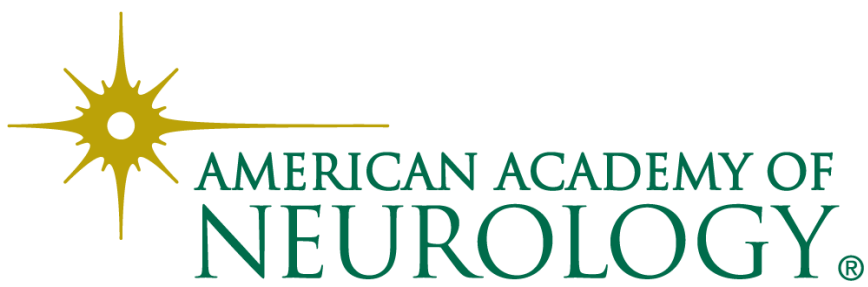

